Review Article

\title{
Simulated laughter techniques for therapeutic use in mental health
}

\begin{abstract}
Laughter has shown quantifiable psychological and psychological positive effects on certain aspects of health. Therapeutic laughter can be used in mental health with preventive intent (life-style medicine) or complementary/alternative approach to other established therapeutic strategies, and can be lumped into the following three groups:

1. Spontaneous laughter.

2. Simulated laughter.

3. Stimulated laughter.

Current laughter therapy is mainly aimed at experiencing the binomial simulatedspontaneous laughter so as to achieve all its health benefits. Simulated laughter is based on the knowledge that the body cannot distinguish between simulated and spontaneous laughter; therefore, their corresponding health effects are alleged to be alike. Either way health-related outcomes are produced. Indeed, simulated laughter may lead to a higher laughter dose (greater intensity and duration at will) which might create greater health outcomes. The effective use of simulated laughter (and other laughter techniques) for therapeutic purposes in mental health needs to be learned, practiced, and developed as any other therapeutic strategy.
\end{abstract}

Therapeutic simulated laughter is thus a modern approach whose fundamentals are the following:

1. Laughter experience is based on well-defined methods, which results in less clinical practice variability, as compared to other laughter interventions.

2. Safe, easy to practice and share.

3. No thinking is required; it fosters joy.

4. It is contagious and can easily be converted into spontaneous laughter when experienced in a group.

5. It allows full therapeutic laughter experience at proper duration and intensity.

Simulated laughter techniques consist of different exercises within every stage of laughter sessions. The library of simulated laughter exercises is virtually infinite. Simulated laughter techniques can be easily implemented and cost-effective for therapeutic use in mental health. Therapeutic simulated laughter is entirely feasible and appears to be the most realistic, sustainable and generalizable laughter intervention to be used in clinical practice and future laughter research.

Keywords: laughter/humor therapy, simulated laughter, laughter intervention, laughter yoga, laughter session, complementary/alternative medicine, lifestyle medicine, positive psychology, clinical practice, mental health
Volume 8 Issue 2 - 2017

Ramon Mora Ripoll

Lifestyle Medicine Network, Spain

Correspondence: Ramon Mora-Ripoll, Lifestyle Medicine Network, Spain, Email ramon.morari@gmail.com

Received: September 28, 2017 | Published: October 10, 2017

\section{Introduction}

Laughter may have both preventive (life-style medicine) and therapeutic values. The biomedical literature available to date supports different indications and health benefits of humor/laughter therapy, ${ }^{1-6}$ which depend not only on the expression of laughter itself, but also on the underlying positive emotions (hilarity-humor, joy, euphoria, fun, well-being, optimism, satisfaction, and many others). There are probably many forms of laughter as individual differences and potential moods, ${ }^{7}$ Any kind of laughter has not been reported as more therapeutic than other; however, therapeutic laughter must include a combination of body, mind and be willing, and can be lumped into the following three groups: ${ }^{8}$

\section{Genuine or spontaneous laughter.}

2. Simulated laughter.

3. Stimulated laughter.

Spontaneous laughter, unrelated to one's own free will, is triggered by different (external) stimuli and positive emotions. Simulated laughter is triggered by oneself at will (self-induced, self-initiated, voluntary), with no specific reason (purposeful, unconditional), and therefore not elicited by humor, fun, other stimuli or positive emotions. And stimulated laughter happens as a result of the physical contact or action (reflex) of certain external stimuli (tickle, hugs, massages, others). Therapeutic value of laughter would concern in particular the first two types, spontaneous and simulated laughter, and to a lesser extent, stimulated laughter. ${ }^{8}$ 
Therapeutic laughter has shown a positive effect on mental health. ${ }^{4-14}$ Indeed, some research has also explored the predictive potential of laughter as a diagnostic tool in the onset and evolution of depression and, potentially, of neuropsychiatric disorders. Therapeutic laughter is usually adequate in the different age groups and in different conditions and clinical setting $\mathrm{s}^{5-18}$ and universally well tolerated, with very limited side effects and contraindications.${ }^{19}$ Once it has been estimated that a laughter intervention may be indicated for an individual or a group, its effective use for preventive or therapeutic purposes needs to be learned and practiced as any other therapeutic strategy. Inviting and facilitating laughter techniques in therapy is not the same as developing and using humor to make the patient laugh. Humor is not necessary to have subsequent laughter. Adults can laugh without it as do infants and children. Health care professionals do not have to be stand-up comics, clowns or magicians to bring laughter into clinical settings. ${ }^{20,21}$ Just by acknowledging how important laughter can be, and having a cheerful and spirited approach is a good place to start. To achieve significant mental health effects, laughter needs to be of sufficient duration and intensity. Taking into account possible age and gender differences may also help improve the relationship with the patient and optimize laughter interventions in the clinical setting. Modern therapeutic laughter, as a noninvasive and non-pharmacological intervention, is mainly based on achieving the binomial simulated-spontaneous laughter, alone or most commonly in a group, so as to experience all its health benefits. Simulated laughter is currently a growing field of scientific research and getting increasingly popular worldwide since it is the foundation of the Laughter Club movement (Laughter Yoga ${ }^{22}$ ) and others. The aim of this review was to discuss and describe the different simulated laughter techniques for therapeutic use in mental health. To our knowledge, this is the first review to be conducted specifically on this subject.

\section{Discussion}

Simulated laughter, as a type of therapeutic laughter, has also shown some quantifiable effects on certain aspects of health, including mental health; ${ }^{9-25}$ however, current empirical data for all its benefits is more limited, as compared to spontaneous laughter, and further research is warranted. Simulated laughter techniques are based on the knowledge that the body cannot distinguish between spontaneous and simulated laughter; therefore, their corresponding health-related benefits are alleged to be alike provided the simulated laughter is experienced with a minimum of enthusiasm. Either way healthrelated outcomes are deemed to be produced. Although the laughter experienced in simulated laughter techniques is firstly voluntary, selfinitiated or self-induced, the corresponding laughter exercises enable the act of making eye contact when performed in a group, enacting playful behaviors and emotional wellness (positive emotions), and being highly contagious from/to other participants, which generally transitions the laughter itself from laughter that is initially simulated to laughter that becomes spontaneous. Indeed, simulated laughter may lead to increased intensity and duration of laughter, both through intentionally self-initiating deep and extended laughter at will, and through shifting into spontaneous laughter triggered through the eye contact, playful behaviors, positive emotions, and contagion experienced and shared among participants. These two concomitant effects have the potential to result in increased "laughter exposure" and greater accompanying health outcomes. ${ }^{9}$

Simulated laughter fundamentals for therapeutic use in clinical practice, including mental health, are as follows:

1. It is based on well-defined techniques and corresponding exercises

2. It is easy and anybody can do it. No thinking is required.

\section{It fosters joy and it is empowering.}

4. It is socially and emotionally safe.

5. It is transmittable.

6. It can easily be converted into spontaneous laughter when experienced in a group.

7. It helps dissolve inhibition and release of laughter, serve as a warm-up practice, and allow full therapeutic laughter experience at proper duration and intensity so as to achieve all its health benefits. ${ }^{9}$

The following five rules are to be advised to patients or participants prior to starting simulated laughter techniques, ${ }^{26}$

1. No new pain: respect one's body. Nothing should be painful or uncomfortable.

2. Fake is fine: whether genuinely laughing or not makes little difference. Either way everybody will benefit from the exercise.

3. Maintain eye contact: this is very important and helps keeping one's mind into the "here now". Also, laughter is visually very contagious.

4. No talking: talking or joking sabotages one's own laughter potential. Let it flow freely.

5. Act happy, joyful and energetic, and move around: interact with others, smile and let everybody hear everybody's laughs. A joyful spirit is noisy. Acting this way will help make everybody feel just like it.

An individual laughter session within a therapeutic laughter intervention typically consists of three stages: ${ }^{27}$

\section{Opening and warm-up.}

\section{Experiencing positive emotions, humor and laughter.}

\section{Recovery, closure and evaluation.}

The pace and content (laughter techniques) of each session is adapted to suit the needs and requirements of the group participating. The duration of an individual laughter session usually ranges between a minimum of 20 minutes and a maximum of 2 hours, at least twice a week during a minimum of 6-8weeks8 (laughter intervention). Laughter should be experienced for at least 3 minutes in total per individual session. Since simulated laughter experience is based on well-defined techniques and corresponding exercises, its methodological/therapeutic approach appears to be less therapistdependent among different laughter therapists and across different laughter sessions; therefore, less clinical practice variability is likely to be found, as compared to other therapeutic laughter interventions. Indeed, simulated laughter techniques may help clinical therapists both to preclude laughter absence (as some individuals exposed to other laughter techniques do not always laugh) and to better adjust laughter for its proper intensity and duration, since laughter may not be able to be prescribed and followed at a conventional 'dose level'. Therefore, therapeutic simulated laughter, as compared to other therapeutic laughter techniques, appears to be the most sustainable and generalizable laughter intervention to be employed in clinical practice and future laughter research. ${ }^{9}$

Table 1 summarizes the different laughter techniques and corresponding exercises (list is complete but not exhaustive), most commonly implemented in a group, by which the clinical therapist can 
generate therapeutic simulated laughter within every stage of laughter sessions for mental health purposes, which may be either used alone or combined with additional spontaneous or stimulated laughter techniques. Solo laughter refers to a series of different simulated laughter exercises for laughing alone in any place or condition (i.e. when laughing in a group may not be feasible, for those unable to move and exercise). Solo laughter also helps develop a positive conditioning of joy and bodily experience of laughter by doing laughter and breathing exercises without having to go and participate in a therapeutic laughter group. There is no one way of laughing alone and the clinical therapist helps develop everybody's own comfort zone with different sounds, gestures, postures, and exercises which work best to facilitate laughter. Laughter Yoga ${ }^{22}$ stands for a set of simulated laughter techniques and corresponding exercises, most usually performed in a group, which are combined with a series of simple and gentle exercises that are repeated one after the other and progressively infused with a lot of childlike playfulness. Most laughter yoga sessions commonly last about 20-30minutes, and up to 45 minutes as they add a laughter meditation at the end of their regular session. The Laughter Wellness method ${ }^{28}$ is a Western evolution of laughter yoga sessions, designed to amplify a positive attitude, which integrates the best of numerous other similar modalities in a cohesive and fluid whole that is easy to implement. In summary, the library of therapeutic simulated laughter techniques and corresponding exercises is virtually infinite, ${ }^{27}$ and by considering many different possibilities and combinations with additional therapeutic techniques, further exercises can be developed and added: for different age groups (children, adults, seniors); to laugh standing up, on a chair, lying on the floor; with or without props, with music, dance, movement, using different body parts; depending on level of physical fitness, underlying health conditions, or preventive or therapeutic aims.

\section{Conclusion}

Laughter, along with other preventive and therapeutic interventions, is a sound prescription as a wonderful way to enhance mental health. ${ }^{3-29}$ Moreover, proponents of 'positive psychology' have identified humor and laughter as one of the 24 positive personal values and attributes. ${ }^{30,31}$ Hence laughter interventions deserve a special place in the clinical setting. ${ }^{32-34}$ Therapeutic simulated laughter is a modern approach based on the knowledge that the body cannot distinguish between spontaneous and simulated laughter; therefore, their corresponding health-related benefits are alleged to be alike. Simulated laughter has also shown some quantifiable effects on certain aspects of health, including mental health. The library of simulated laughter exercises is virtually infinite. Unlike other therapies which are more time-consuming, committed or expensive, simulated laughter techniques can be easily implemented and cost-effective for therapeutic use in mental health. Therapeutic simulated laughter is entirely feasible and appears to be the most realistic, sustainable and generalizable laughter intervention to be applied in clinical practice and future laughter research.

\section{Acknowledgements}

None.

\section{Conflicts of interest}

Author declares there are no conflicts of interest.

\section{Funding}

None.

\section{References}

1. Martin RA. Humor, laughter, and physical health: methodological issues and research findings. Pyschol Bull. 2001;127(4):504-519.

2. Martin RA, Lefcourt HM. Sense of humor and physical health: theoretical issues recent findings, and future directions. Humor. 2004;17(1):1-20.

3. Berk R, Martin R, Baird D, et al. What everyone should know about humor and laughter. Association for Applied and Therapeutic Humor (AATH), USA. 2008. p. 1.

4. Mora-Ripoll R. The therapeutic value of laughter in medicine. Altern Ther Health Med. 2010;16(6):56-64.

5. Mora-Ripoll R. La risa como tratamiento médico: una opción alternativa/ complementaria en educación y atención sanitarias. Med Clin (Barc). 2011;136(3):111-115.

6. Martin R, Kuiper NA. Three decades investigating humor and laughter. An interview with Professor Rod Martin. Eur J Psychol. 2016;12(3):498-512.

7. Provine RR. Laughter as a scientific problem: an adventure in sidewalk neuroscience. J Comp Neurol. 2016;524(8):1532-1539.

8. Mora-Ripoll R. Medicina y terapia de la risa Manual. Desclée de Brouwer, Spain. 2010. p.1-184.

9. Mora-Ripoll R. Potential health benefits of simulated laughter: a narrative review of the literature and recommendations for future research. Complement Ther Med. 2011;19(3):170-177.

10. García-Rodera MC. Gran libro de la risoterapia. El poder de la risa. Ediciones Hontanar, Spain. 2015. p.1-334

11. Ko HJ, Youn $\mathrm{CH}$. Effects of laughter therapy on depression, cognition and sleep among the community-dwelling elderly. Geriatr Gerontol Int. 2011;11(3):267-274.

12. Rudnick A, Kohn PM, Edwards KR, et al. Humour-related interventions for people with mental illness: a randomized controlled pilot study. Community Ment Health J. 2014;50(6):737-42.

13. Kim SH, Kim YH, Kim HJ. Laughter and stress relief in cancer patients: a pilot study. Evidence-Based Complementary and Alternative Medicine ID. 2015;864739:1-6.

14. Yim J. Therapeutic benefits of laughter in mental health: a theoretical review. Tohoku J Exp Med. 2016;239(3):243-249.

15. Navarro J, del Moral R, Alonso MF, et al. Validation of laughter for diagnosis and evaluaron of depression. J Affect Disord. 2014;160:43-49.

16. Holden R. La risa, la mejor medicina. Oniro, Spain. 2004. p.1-144.

17. Temprano E. El arte de la risa. Seix Barral, Spain. 1999. p.1-256.

18. García Larrauri B. Programa para mejorar el sentido del humor. (1st edn), Ediciones Pirámide, Spain. 2008. p.1-344.

19. Ferner RE, Aronson JK. Laughter and MIRTH (Methodological Investigation of Risibility, Therapeutic and Harmful): narrative synthesis. BMJ. 2013;347:f7274.

20. Mora-Ripoll R, Ubal-López R. La risa: diferencias según género. Rev Clin Esp. 2011;211(7):360-366.

21. Martin RA, Kuiper NA. Daily occurrence of laughter: Relationships with age, gender, and Type A personality. Humor: International Journal of Humor Research. 1999;12(4):355-384.

22. Kataria M. Laugh for no reason. Madhuri International, India. 2011. p.1-232.

23. Ellis JM, Ben-Moshe R, Teshuva K. Laughter yoga activities for older people living in residential aged care homes: a feasibility study. Australas J Ageing. 2017;36(3):E28-E31. 
24. Heo EH, Kim S, Park HJ, et al. The effects of a simulated laughter programme on mood, cortisol levels, and health-related quality of life among haemodialysis patients. Complement Ther Clin Pract. 2016;25:1-7.

25. Greene CM, Morgan JC, Traywick LS, et al. Evaluation of a Laughterbased Exercise Program on Health and Self-efficacy for Exercise. Gerontologist pii: gnw. 2016;105.

26. Gendry S. Laughter FUN-damentals. The ultimate simulated laughter exercises companion book. American School of Laughter Yoga, USA. 2007.

27. Mora-Ripoll R. Laughter techniques for therapeutic use in medicine. $O A$ Alternative Medicine. 2013;1(3):25.

28. Gendry S. [EBOOK] 505 Best of Laughter Exercises. (3rd edn), Laughter Online University, USA. 2015. p.1-62.
29. Strean WB. Laughter prescription. Can Fam Physician. 2009;55(10):965-957.

30. Vera B. Psicología positiva: una nueva forma de entender la psicología. Calamar Ediciones, Spain. 2008. p.1-192.

31. Seligman MCP, Stee RA, Park N, et al. Positive psychology progress: empirical validation of interventions. Am Pyschol. 2005;60(5):410-421.

32. Mora-Ripoll R. La medicina del estilo de vida: la importancia de considerar todas las causas de la enfermedad. Rev Psiquiatr Salud Mental. 2012;5(1):48-52.

33. Rosner F. Therapeutic efficacy of laughter in medicine. Cancer Investigation. 2002;20(3):434-436.

34. Goodman J, Fry WF Jr. Toward optimal health: the experts discuss therapeutic humor. Interview by Jodi R. Godfrey. $J$ Womens Health (Larchmt). 2004;13(5):474-479. 